\title{
Measurement and Evaluation of the Competitiveness of Rural E-commerce of Sichuan Province in China
}

\author{
Guan Wenjin \\ Correspondence: Guan Wenjin, Sichuan Institute of Administration, Chengdu, China. \\ Received: May 6, 2019 \\ doi:10.11114/bms.v5i2.4303 \\ Online Published: May 29, 2019 \\ URL: https://doi.org/10.11114/bms.v5i2.4303
}

\begin{abstract}
The development of rural e-commerce has provided new ideas for provinces and cities to promote rural revitalization. This paper combines the indicators of the competitiveness evaluation system of rural e-commerce established in domestic literature, and chooses 12 basic indicators to analyze the development of rural e-commerce in Sichuan Province. By collecting the data of Sichuan Statistical Yearbook and Statistical Bulletins in Sichuan Province and using factor analysis, this paper aims to find out the key factors affecting the development of rural e-commerce in Sichuan Province, calculates the comprehensive competitiveness scores of rural e-commerce in 21 cities and states of Sichuan Province, and puts forward corresponding suggestions and measures. The results show that the development of rural e-commerce in Sichuan Province is seriously unbalanced. The development of rural e-commerce in Chengdu has absolute advantages in Sichuan Province, but other cities, such as Panzhihua City, have overtaken Chengdu City in some aspects.
\end{abstract}

Keywords: rural e-commerce, factor analysis, competitiveness, measurement

\section{Introduction}

In 2018, China issued the "Opinions on Implementing the Strategy of Rural Revitalization", which pointed out the way for integrating e-commerce into agricultural production, promoting structural reform of agricultural supply side, increasing the income of agricultural workers and realizing agricultural and rural modernization. The government of Sichuan province has vigorously promoted the development of rural e-commerce in the whole province. In 2018, 260 new rural e-commerce demonstration counties were added in China, of which 28 were added in Sichuan Province, ranking first among other provinces in the country. However, there are still some problems need to be solved urgently in the development of rural e-commerce in Sichuan Province, such as: lack of talents with e-commerce operation experience; low brand popularity of agricultural products; weak rural logistics infrastructure, etc. Therefore, accurately evaluating the current situation of rural e-commerce in Sichuan Province and proposing ways and countermeasures to improve the competitiveness of rural e-commerce according to local conditions are of great practical significance for transforming the mode of rural economic development, promoting farmers' income growth and promoting the implementation of the strategy of rural revitalization.

\section{Literature Review}

At present, the literature on rural e-commerce in China mainly focuses on two aspects: rural e-commerce and rural residents entrepreneurship, and the coordinated development of rural e-commerce and express logistics.

\subsection{Rural E-commerce and Rural Residents Entrepreneurship}

Age, educational level and social competence have significant positive effects on farmers' e-commerce cooperative entrepreneurial behavior. The older the age, the higher the educational level, the stronger the social ability of rural residents, the more inclined to engage in rural e-commerce industry. Family labor, the field of e-commerce, and the degree of trust with relatives and friends have a negative impact on farmers' e-commerce cooperative entrepreneurial behavior (Liu Bin et al., 2019) ${ }^{1}$. With its diversification and personality customization, e-commerce has attracted a large number of entrepreneurs. The integration of embedded entrepreneurship and e-commerce in rural communities can fully integrate rural resources and achieve optimal utilization of resources (Han Penghui et al., 2019) ${ }^{2}$. The development of rural e-commerce provides more choices for rural residents to start businesses, promotes a new round of investment, enlarges the original scale of employment in rural areas, and at the same time, the platform for providing rural areas has certain advantages in providing information, resources and even the trust level of rural residents, which makes a large 
amount of social capital flow to rural areas and promotes rural residents to start businesses (Wang Jinjie et al., 2019) . $^{3}$ The characteristics of technology and market environment of e-commerce will improve the education of rural residents to a certain extent, promote their learning and using the Internet, effectively improve the knowledge storage of rural residents, enhance their rational thinking ability, and influence their entrepreneurial choices (Li Qihang et al., 2017)

\subsection{Cooperative Development of Rural E-commerce and Express Logistics}

The development of rural e-commerce plays an important role in promoting economic exchanges between rural areas and urban areas, and in promoting the export of high-quality agricultural products to cities. Rural residents can expand the sales market of their agricultural products through the platform and channels provided by e-commerce, in which express delivery and logistics play an indispensable part (Li Bo, 2018) ${ }^{5}$. However, compared with urban areas, rural areas are still lagging behind in transportation network coverage or other infrastructure facilities, which is not conducive to the development of e-commerce based on logistics and distribution services (Yu Shuang et al., 2017) ${ }^{6}$. The concentration of commercial outlets in rural areas is relatively poor, the development structure of retail industry is relatively single, the development of commercial flow and logistics in commercial circulation industry is slow, the integration degree is relatively low, and the lack of professionals are the major problems in the development of rural e-commerce in China (Wu Feng et al., 2017)7. The emergence of rural e-commerce can not be separated from the logistics situation in rural areas, the basic literacy of rural residents and policy support, but in order to achieve further development, it depends on the quality of agricultural products and the consistency of supply and demand categories

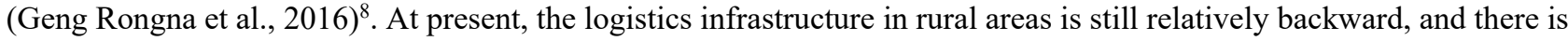
no developed road network. Goods circulation is not only inefficient but also costly. The logistics part of e-commerce in rural areas relies on the third-party logistics distribution (Luo Shulin, 2016) ${ }^{9}$. There are three main scenarios of agricultural product logistics in China. One is for the transportation of agricultural products in wholesale markets, the other is for the connection between agriculture and supermarkets, and the third is for agricultural products e-commerce. In the application scenario of agricultural e-commerce, farmers publish agricultural products information on the sharing platform. After the online transaction is completed, the express logistics company directly delivers agricultural products to customers (Shang Ronghua, 2014) ${ }^{10}$. On the one hand, the coordinated development of rural e-commerce and express logistics can promote the rapid development of rural e-commerce, on the other hand, it also promotes the transformation and upgrading of express industry in rural areas. Promoting economic restructuring in rural areas and the development of high-quality and efficient agricultural modernization industry (Sun Zhanquan, 2019) ${ }^{11}$.

At present, the existing literature seldom involves the evaluation of the competitiveness of rural e-commerce in a region. This paper uses factor analysis method, combines the data of "Sichuan Statistical Yearbook 2016" and the "Statistical Bulletins of Sichuan provincial cities and states 2016", to comprehensively evaluate the competitiveness of rural e-commerce in Sichuan Province, and further analyses the strengths and weaknesses of each city and state in the competitiveness of rural e-commerce.

\section{Theoretical Definition}

Rural E-commerce refers to building a compact and orderly business consortium through market-oriented operation and multi-regional cooperation by virtue of the advantages of the Internet and digital technology, so as to reduce the cost of rural business and expand the field of rural business. Competitiveness is a kind of comprehensive ability embodied by competition or comparison between two or more participants. The development of rural e-commerce has three advantages:

One is to change the mode of agricultural production. The traditional agricultural market is mainly production-oriented. Agricultural producers can not clearly understand the specific needs of the market. With the development of rural e-commerce, market demand information is rapidly conveyed, making full use of the advantages of e-commerce, combining with consumer demand to engage in agricultural production activities, promoting the structural reform of agricultural and rural supply side, which is conducive to improving the efficiency of agricultural product supply and promoting implementation the strategy of rural revitalization and the modernization of agriculture and countryside;

The second is to improve the supply capacity of rural public services. With the development of rural e-commerce, the Internet situation in rural areas has been greatly improved. Since 2014, through financial and social capital investment, rural e-commerce has been promoted to enter villages and households in many places, and the establishment of a smooth Internet and agricultural information society has laid the foundation for the development of rural e-commerce;

Third, to improve the living standards of farmers. The development of rural e-commerce, on the one hand, is conducive to the diversified choice of consumers, on the other hand, is conducive to increasing the income of agricultural producers and improving the living standards of farmers; due to market intervention, effectively regulating the supply and demand of agricultural products, the mismatch between supply and demand of agricultural products has been improved, at the same time, the transaction volume of agricultural products has been greatly increased, and farmers 
have realized income increase. Modern Internet means such as promotion of rural tourist attractions, cultural heritage exhibition, accommodation reservation and mobile payment have entered rural areas one after another, and farmers' income has been further guaranteed.

\section{Comprehensive Evaluation of Rural E-commerce Competitiveness}

\subsection{Selection of Index System}

The index of this paper refers to the existing rural e-commerce evaluation system literature. Liu Hong and Ai Chunmei constructed the evaluation system of rural e-commerce in China from three aspects: the readiness, application and influence of rural e-commerce, and further put forward eight secondary indicators and 25 third-level indicators ${ }^{12}$. Zhang Xiaoli constructed an evaluation system from six aspects: macro-analysis of the specific application of rural information, government support analysis, development of rural infrastructure, speed of rural information resources dissemination, consumption of rural information subjects and application of rural e-commerce ${ }^{13}$. Zheng Yaqin and Zheng Wensheng constructed the evaluation system from six aspects: the macro-security level of rural information application, the government's support level for the development of information technology, the level of rural information infrastructure, the level of rural information resources and dissemination, the level of rural information subject and information consumption, and the level of rural e-commerce application ${ }^{14}$. Based on the existing literature, this paper finally chooses 12 indicators of rural e-commerce competitiveness: GDP per capita (X1), GDP growth rate (X2), gross domestic product of primary industry (X3), primary industry contribution rate (X4), population urbanization rate (X5), total postal and telecommunications business (X6), price index of transportation and communication supplies (X7), Internet penetration rate (X8), total number of mobile phones per 100 households (X9), proportion of primary industry in fixed investment (X10), disposable income of rural population (X11), proportion of primary industry employees (X12), the specific indicators are shown in table 1.

Table 1. Indicators of rural e-commerce competitiveness

\begin{tabular}{ll}
\hline INDICATORS & VARIABLE \\
\hline GDP per capita/yuan & $\mathrm{X} 1$ \\
GDP growth rate/\% & $\mathrm{X} 2$ \\
Gross domestic product of primary industry & $\mathrm{X} 3$ \\
contribution rate of primary industry $/ \%$ & $\mathrm{X} 4$ \\
urbanization rate of population/\% & $\mathrm{X} 5$ \\
Total Posts and Telecommunications Business/ Billion yuan & $\mathrm{X} 6$ \\
Price Index of Transportation and Communications Supplies & $\mathrm{X} 7$ \\
Internet penetration rate/\% & $\mathrm{X} 8$ \\
Total number of mobile phones per 100 Households & $\mathrm{X} 9$ \\
The proportion of primary industry in fixed investment & $\mathrm{X} 10$ \\
Disposable Income of Rural Population & $\mathrm{X} 11$ \\
The proportion of employees in the primary industry & $\mathrm{X} 12$ \\
\hline 4.2 Data Descriptive Statistics &
\end{tabular}

4.2 Data Descriptive Statistics

The data in this paper are from "Sichuan Statistical Yearbook 2016" and the "Statistical Bulletins of cities and states 2016". For missing data, this paper adopts the application of sequence average value to replace. Specific data descriptive statistics are as follows Table 2. 
Table 2. Data Description Statistics

\begin{tabular}{lllllll}
\hline Variable & Number & Minimum Value & $\begin{array}{l}\text { Maximum } \\
\text { Value }\end{array}$ & Average Value & $\begin{array}{l}\text { Standard } \\
\text { Deviation }\end{array}$ & Variance \\
\hline X1 & 21 & 16405 & 82221 & 37471.81 & 16101.349 & 259253452.9 \\
X2 & 21 & -0.257356067 & 0.126752127 & 0.0688056891 & 0.0759572344 & 0.006 \\
X3 & 21 & 34.25 & 474.94 & 184.93 & 109.94 & 12087.218 \\
X4 & 21 & 0.0337544842 & 0.25791993 & 0.148829985 & 0.0519551281 & 0.003 \\
X5 & 21 & 29.26 & 70.62 & 45.52980215 & 9.242586478 & 85.425 \\
X6 & 21 & 7.46 & 709.3 & 70.80714286 & 148.7924592 & 22139.196 \\
X7 & 21 & 93.2 & 100.2 & 96.586 & 2.0372 & 4.150 \\
X8 & 17 & 229.8 & 12170.23 & 1824.425882 & 2709.094823 & 7339194.759 \\
X9 & 20 & 53.70944993 & 151.1936173 & 88.7782042 & 23.76444121 & 564.749 \\
X10 & 21 & 0.0165629049 & 0.109433112 & 0.0443624629 & 0.020647521 & 0.000 \\
X11 & 21 & 9367 & 18605 & 12463.00 & 2082.828 & 4338171.800 \\
X12 & 19 & 0.12544652 & 0.590005132 & 0.409087613 & 0.101989754 & 0.010 \\
\hline
\end{tabular}

4.3 Factor Analysis

Combining with the existing literature, this paper explores a more concise evaluation system of rural e-commerce, synthesizes the existing literature, and finally selects the existing evaluation system of 12 indicators. This paper uses SPSS Statistics 24 software for factor analysis to reduce dimensionality of existing evaluation system. In order to eliminate the influence of each data dimension, this paper first standardizes the original data. KMO test and Bartlett spherical test were carried out by SPSS Statistics 24 software with 12 standardized indexes as variables. The test results are shown in Table 3. KMO value is 0.726, greater than 0.5, which indicates that factor analysis is applicable; Bartlett spherical test approximate chi-square value is 220.115 , P value is less than 0.001 to reach a significant level.

Table 3. KMO test and Bartlett spherical test

\begin{tabular}{lll}
\hline KMO test & & 0.726 \\
\hline \multirow{3}{*}{ Bartlett spherical test } & approximate chi square & 220.115 \\
& degree of freedom & 66 \\
& saliency & 0.000 \\
\hline
\end{tabular}

Then common factors are extracted. SPSS Statistics 24 software was used to analyze the variables selected by 21 cities and states in Sichuan Province. The eigenvalues and contribution rates of each factor were calculated as shown in Table 4.

Table 4. Factor eigenvalues and contribution rates

\begin{tabular}{|c|c|c|c|c|c|c|c|c|c|}
\hline \multirow[b]{2}{*}{ Variable } & \multicolumn{3}{|c|}{ Initial eigenvalue } & \multicolumn{3}{|c|}{ Extracting Square Sum of Load } & \multicolumn{3}{|c|}{ Square Sum of Rotating Load } \\
\hline & Total & $\begin{array}{l}\text { Percentage } \\
\text { of } \\
\text { variance }\end{array}$ & Accumulate $/ \%$ & Total & $\begin{array}{l}\text { Percenta } \\
\text { of } \\
\text { variance }\end{array}$ & Accumulate $/ \%$ & Total & $\begin{array}{l}\text { Percentage } \\
\text { of } \\
\text { variance }\end{array}$ & Accumulate $/ \%$ \\
\hline 1 & 6.371 & 53.093 & 53.093 & 6.371 & 53.093 & 53.093 & 4.777 & 39.811 & 39.811 \\
\hline 2 & 1.656 & 13.803 & 66.896 & 1.656 & 13.803 & 66.896 & 2.781 & 23.171 & 62.982 \\
\hline 3 & 1.222 & 10.187 & 77.083 & 1.222 & 10.187 & 77.083 & 1.535 & 12.788 & 75.770 \\
\hline 4 & 0.967 & 8.060 & 85.143 & 0.967 & 8.060 & 85.143 & 1.125 & 9.372 & 85.143 \\
\hline 5 & 0.687 & 5.722 & 90.865 & & & & & & \\
\hline 6 & 0.382 & 3.183 & 94.047 & & & & & & \\
\hline 7 & 0.272 & 2.263 & 96.310 & & & & & & \\
\hline 8 & 0.211 & 1.757 & 98.067 & & & & & & \\
\hline 9 & 0.131 & 1.094 & 99.161 & & & & & & \\
\hline 10 & 0.063 & 0.529 & 99.690 & & & & & & \\
\hline 11 & 0.024 & 0.199 & 99.888 & & & & & & \\
\hline 12 & 0.013 & 0.112 & 100.000 & & & & & & \\
\hline
\end{tabular}

\subsection{Factor Rotation}

The factor load matrix directly calculated by SPSS Statistics 24 software is shown in Table 5. From Table 5, it can be seen that some variables have large loads on many factors and can not be named accurately. Therefore, the factor 
rotation is continued in this paper. The factor load matrix after rotation is shown in Table 6. From Table 6, we can see that GDP per capita (X1), contribution rate of primary industry (X4), urbanization rate of population (X5), total number of mobile phones per 100 households (X9), disposable income of rural population (X11), and the proportion of primary industry employees (X12) have a larger factor load on the common factor $F_{1}$. These indicators mainly reflect the basic environmental conditions of rural e-commerce development, so the common factor $F_{1}$ is named rural e-commerce environment. The factor loads of primary industry gross product (X3), total postal and telecommunication business (X6) and Internet penetration rate (X8) on the common factor $F_{2}$ are larger. These indicators mainly reflect the logistics and communication conditions of rural e-commerce development. Therefore, the common factor $F_{2}$ is named as rural infrastructure. The growth rate of GDP (X2) and the proportion of primary industry in fixed investment (X10) are heavily loaded on the common factor $F_{3}$, which mainly reflects the development of rural agriculture. Therefore, the common factor $F_{3}$ is named rural agricultural development. The price index of transportation and communication supplies (X7) has a large factor load on the common factor $F_{4}$, which mainly reflects the cost of rural e-commerce development. Therefore, the common factor $F_{4}$ is named as the cost of rural e-commerce.

Table 5. Factorial Load Matrix

\begin{tabular}{|c|c|c|c|c|}
\hline \multirow{2}{*}{ Variable } & \multicolumn{4}{|c|}{ Common Factor } \\
\hline & 1 & 2 & 3 & 4 \\
\hline $\mathrm{X} 5$ & 0.923 & -0.285 & -0.065 & 0.018 \\
\hline X11 & 0.870 & -0.128 & 0.271 & -0.004 \\
\hline $\mathrm{X} 8$ & 0.865 & 0.299 & 0.255 & -0.029 \\
\hline X6 & 0.862 & 0.338 & 0.233 & 0.011 \\
\hline $\mathrm{X} 1$ & 0.852 & -0.380 & -0.064 & 0.074 \\
\hline $\mathrm{X} 9$ & 0.830 & 0.112 & -0.206 & -0.302 \\
\hline $\mathrm{X} 12$ & -0.827 & 0.017 & 0.134 & -0.014 \\
\hline $\mathrm{X} 4$ & -0.791 & 0.494 & 0.114 & 0.232 \\
\hline $\mathrm{X} 10$ & -0.200 & -0.639 & 0.393 & -0.248 \\
\hline $\mathrm{X} 3$ & 0.531 & 0.600 & 0.422 & 0.138 \\
\hline $\mathrm{X} 2$ & 0.308 & 0.345 & -0.750 & -0.206 \\
\hline $\mathrm{X} 7$ & 0.362 & -0.257 & -0.228 & 0.832 \\
\hline
\end{tabular}

Table 6. Factorial load matrix after rotation

\begin{tabular}{|c|c|c|c|c|}
\hline \multirow{2}{*}{ Variable } & \multicolumn{4}{|c|}{ Common Factor } \\
\hline & 1 & 2 & 3 & 4 \\
\hline $\mathrm{X} 4$ & -0.968 & 0.003 & 0.014 & -0.012 \\
\hline $\mathrm{X} 5$ & 0.902 & 0.262 & 0.068 & 0.223 \\
\hline $\mathrm{X} 1$ & 0.877 & 0.173 & -0.003 & 0.283 \\
\hline $\mathrm{X} 11$ & 0.744 & 0.515 & -0.127 & 0.104 \\
\hline X9 & 0.727 & 0.346 & 0.407 & -0.146 \\
\hline $\mathrm{X} 12$ & -0.700 & -0.347 & -0.254 & -0.167 \\
\hline $\mathrm{X} 3$ & 0.049 & 0.911 & 0.079 & 0.026 \\
\hline $\mathrm{X} 6$ & 0.506 & 0.792 & 0.159 & 0.038 \\
\hline $\mathrm{X} 8$ & 0.535 & 0.775 & 0.123 & 0.003 \\
\hline $\mathrm{X} 2$ & 0.227 & -0.057 & 0.871 & -0.080 \\
\hline $\mathrm{X} 10$ & 0.167 & -0.336 & -0.690 & -0.219 \\
\hline $\mathrm{X} 7$ & 0.244 & 0.018 & 0.050 & 0.937 \\
\hline
\end{tabular}




\subsection{Calculating Factor Score}

The factor score coefficient matrix calculated by SPSS Statistics 24 is shown in Table 7. According to the factor score coefficient and the following formula, the scores of each common factor can be calculated

$$
F_{i}=\sum_{j=1}^{12} w_{j} X_{j}
$$

In the formula, $F_{i}$ is the common factor $\mathrm{I}, \mathrm{I}=1,2,3,4 ; w_{j}$ is the score coefficient of the $\mathrm{j}$ original variable on the $\mathrm{I}$ common factor; $X_{j}$ is the original variable $\mathrm{J}$.

Table 7. Factor score coefficient matrix

\begin{tabular}{|c|c|c|c|c|}
\hline \multirow{2}{*}{ Variable } & \multicolumn{4}{|c|}{ Common Factor } \\
\hline & 1 & 2 & 3 & 4 \\
\hline $\mathrm{X} 1$ & 0.211 & -0.096 & -0.064 & 0.145 \\
\hline $\mathrm{X} 2$ & 0.067 & -0.206 & 0.637 & -0.125 \\
\hline $\mathrm{X} 3$ & -0.192 & 0.485 & -0.074 & 0.020 \\
\hline $\mathrm{X} 4$ & -0.322 & 0.213 & 0.048 & 0.138 \\
\hline $\mathrm{X} 5$ & 0.206 & -0.062 & -0.026 & 0.082 \\
\hline X6 & -0.018 & 0.307 & -0.017 & -0.040 \\
\hline $\mathrm{X} 7$ & -0.069 & -0.048 & 0.013 & 0.892 \\
\hline $\mathrm{X} 8$ & 0.003 & 0.296 & -0.042 & -0.079 \\
\hline $\mathrm{X} 9$ & 0.173 & -0.026 & 0.221 & -0.260 \\
\hline $\mathrm{X} 10$ & 0.191 & -0.126 & -0.460 & -0.235 \\
\hline $\mathrm{X} 11$ & 0.124 & 0.141 & -0.196 & -0.008 \\
\hline $\mathrm{X} 12$ & -0.122 & -0.003 & -0.107 & -0.055 \\
\hline \multicolumn{5}{|c|}{$\begin{aligned} F_{1}=0.211 X_{1}+ & 0.067 X_{2}-0.192 X_{3}-0.322 X_{4}+0.206 X_{5}-0.018 X_{6}-0.069 X_{7}+0.003 X_{8}+0.173 X_{9}+0.191 X_{10} \\
& +0.124 X_{11}-0.122 X_{12}\end{aligned}$} \\
\hline \multicolumn{5}{|c|}{$\begin{array}{c}F_{2}=-0.096 X_{1}-0.206 X_{2}+0.485 X_{3}+0.213 X_{4}-0.062 X_{5}+0.307 X_{6}-0.048 X_{7}+0.296 X_{8}-0.026 X_{9} \\
-0.126 X_{10}+0.141 X_{11}-0.003 X_{12}\end{array}$} \\
\hline \multicolumn{5}{|c|}{$\begin{aligned} F_{3}=-0.064 X_{1}+ & 0.637 X_{2}-0.074 X_{3}+0.048 X_{4}-0.026 X_{5}-0.017 X_{6}+0.013 X_{7}-0.042 X_{8}+0.221 X_{9}-0.46 X_{10} \\
& -0.196 X_{11}-0.107 X_{12}\end{aligned}$} \\
\hline \multicolumn{5}{|c|}{$\begin{aligned} F_{4}=0.145 X_{1}- & 0.125 X_{2}+0.02 X_{3}+0.138 X_{4}+0.082 X_{5}-0.04 X_{6}+0.892 X_{7}-0.079 X_{8}-0.26 X_{9}-0.235 X_{10} \\
& -0.008 X_{11}-0.055 X_{12}\end{aligned}$} \\
\hline
\end{tabular}

After calculating the common factor scores, combined with the variance contribution rate of each common factor in Table 4, we can calculate the sample comprehensive score Z, in which the weight coefficient of each common factor is the factor variance contribution rate after rotation.

$$
\mathrm{Z}=0.39811 F_{1}+0.23171 F_{2}+0.12788 F_{3}+0.09372 F_{4}
$$

The higher the comprehensive score, the stronger the competitiveness of rural e-commerce in this region. Through the above formula, we can rank the scores of 21 cities and states in Sichuan Province. The ranking results are shown in Table 8. 
Table 8. Comprehensive ranking of rural e-commerce competitiveness of cities and states

\begin{tabular}{l|lllll|l}
\hline Region & F1 & F2 & F3 & F4 & Z & Ranking \\
\hline Chengdu & 2.14997 & 3.298841 & 0.563772 & 0.271177 & 1.622131 & 1 \\
Panzhihua & 2.15563 & -1.79412 & 0.142915 & 1.828618 & 0.445595 & 2 \\
Mianyang & 0.384956 & 0.55762 & 0.141717 & -1.60982 & 0.279727 & 3 \\
Zigong & 1.139067 & -0.89737 & -1.43212 & -0.22876 & 0.24947 & 4 \\
Deyang & 0.442901 & 0.063939 & 0.80499 & 0.692524 & 0.19782 & 5 \\
Leshan & 0.597163 & -0.47344 & 0.39434 & 0.365791 & 0.129765 & 6 \\
Meishan & 0.15636 & 0.070079 & 0.251961 & -0.72312 & 0.076303 & 7 \\
Yibin & 0.038553 & 0.156358 & -0.06994 & -0.59946 & 0.052081 & 8 \\
Luzhou & 0.294595 & -0.31436 & 0.167531 & -0.73197 & 0.042972 & 9 \\
Neijiang & -0.00426 & -0.0105 & -0.15009 & -0.12541 & -0.0039 & 10 \\
Ziyang & -0.53974 & 0.573222 & -3.78888 & 0.605021 & -0.10953 & 11 \\
Yaan & 0.142044 & -0.70171 & 0.493503 & -0.88661 & -0.11129 & 12 \\
Guangan & -0.34501 & -0.10561 & -0.00063 & -0.73578 & -0.16182 & 13 \\
Guangyuan & -0.09973 & -0.5974 & 0.120731 & -1.28271 & -0.17998 & 14 \\
Suining & -0.31985 & -0.41463 & 0.180701 & 1.560077 & -0.22003 & 15 \\
Nanchong & -1.17901 & 0.98647 & 0.702612 & 1.772146 & -0.22588 & 16 \\
Dazhou & -1.06519 & 0.65098 & -0.51978 & 0.331871 & -0.27529 & 17 \\
Aba Tibetan and Qiang Autonomous Prefecture & -0.2415 & -0.81352 & 0.495003 & -0.39944 & -0.28701 & 18 \\
Bazhong & -0.46721 & -0.62281 & 0.163417 & -0.81906 & -0.33192 & 19 \\
Liangshan Yi Autonomous Prefecture & -1.54834 & 0.721621 & 0.45372 & -0.58818 & -0.4524 & 20 \\
Ganzi Tibetan Autonomous Prefecture & -1.69142 & -0.33365 & 0.884548 & 1.303091 & -0.73687 & 21 \\
\hline 5.Resut Analss and Suggestons & & & & & \\
\hline
\end{tabular}

5.Result Analysis and Suggestions

From the comprehensive ranking of rural e-commerce competitiveness of each city and state, we can see that the ranking of each city and state in the competitiveness of rural e-commerce is not completely consistent with the ranking of GDP. As the central city of the western region, Chengdu has obvious advantages in the infrastructure and operation environment of rural e-commerce compared with other cities and states, and ranks first in the overall competitiveness. However, the insufficient investment in rural agriculture development and the high operation cost of rural e-commerce in Chengdu are the shortcomings of the development of rural e-commerce in Chengdu and the key factors restricting the development of rural economy in Chengdu. Increasing investment in agriculture, further reducing the price of Internet communication products in rural areas, and reducing the cost of rural e-commerce operation will help Chengdu's rural e-commerce and even the economic strength of Chengdu to achieve the second high-speed development.

The second city in the list is Panzhihua City. One thing worth noting is that the comprehensive score of rural e-commerce competitiveness of Chengdu City is 1.622, while Panzhihua City is second only to Chengdu City, but the score dropped sharply to 0.446 , which shows that the development of rural e-commerce in Sichuan Province is extremely unbalanced and the regional differentiation is serious. It also reflects that most of the resources in Sichuan Province are inclined to Chengdu. Except Chengdu, other cities and states in Sichuan Province have relatively poor development in rural e-commerce. On the other hand, it can be seen from the score composition of Panzhihua City that although the total score is not high, some aspects still have better development, such as the environment and cost of e-commerce operation in rural areas are excellent, which has been better than Chengdu City in this respect. Panzhihua City scored 2.156 in rural basic e-commerce environment, mainly due to the abundant production of various high-value-added cash crops. Because of its unique topography and climate, Panzhihua City is the only subtropical fruit production base in Sichuan Province. It is rich in high value-added fruits such as mango, loquat, lotus fog, pomegranate, strawberry and cherry, which creates a good environment for rural e-commerce operation. However, the construction of rural infrastructure in Panzhihua City still needs to be improved urgently. The possible reason is that the special geographical conditions of the mountains and valleys of Panzhihua City and the staggered distribution of basins are not conducive to the development of rural Internet and logistics industry, resulting in the lack of rural infrastructure and 
seriously restricting the development of rural e-commerce. If Panzhihua can concentrate its efforts to improve rural infrastructure, the local rural e-commerce will have a leap forward.

According to the analysis, Mianyang's rural e-commerce competitiveness ranks third. However, from the composition of rural e-commerce scoring in Mianyang City, there are no obvious advantages in terms of e-commerce environment, infrastructure, rural development and e-commerce cost. Mianyang City has a balanced score in all aspects. The relative advantage is the construction of rural basic facilities. The relative disadvantage lies in the cost of rural e-commerce. In promoting the development of rural e-commerce in Mianyang City, resources should be more inclined to reduce the price of communication products in rural areas. Accelerate the implementation of the "Speed-up and Fee-Reduction" policy in the national telecommunications industry, and help rural e-commerce develop rapidly in Mianyang City.

The GDP of Zigong City ranks in the middle of Sichuan Province. However, according to the analysis, the competitiveness of rural e-commerce in Zigong City ranks fourth, which is mainly due to the relaxed environment of rural e-commerce in Zigong City. In my opinion, the reason for this phenomenon is that in 2016, the rural population of Zigong City accounted for about $60 \%$ of the city's population, more people engaged in rural work, and the development environment of rural e-commerce is relatively relaxed. However, rural infrastructure, rural agricultural development and rural e-commerce costs are still the bottlenecks which is restricting the development of rural e-commerce in Zigong. Especially in rural agricultural development, the local government can consider expanding the categories of agricultural crops, concentrating on supporting several high-value-added agricultural products, and striving to form brand development. At the same time, reducing the price of communication products in rural areas. Branding of goods and low-cost agricultural industry drive the development of rural e-commerce in Zigong.

In addition to the above four cities, Deyang City, Leshan City, Meishan City, Yibin City and Luzhou City are weaker than the first four cities in the competitiveness of rural e-commerce, but the results show that the comprehensive score of rural e-commerce competitiveness is still greater than 0 . However the comprehensive competitiveness scores of Neijiang City, Ziyang City, Ya'an City, Guang'an City, Guangyuan City, Suining City, Nanchong City, Dazhou City, Aba Tibetan Qiang Autonomous Prefecture, Liangshan Yi Autonomous Prefecture and Ganzi Tibetan Autonomous Prefecture are less than 0 , and the rural e-commerce in these cities and states still needs to focus on development. But on the other hand, the low comprehensive competitiveness score does not mean that these areas have no advantage in developing rural e-commerce. For example, Ziyang City has comparative advantages in rural infrastructure construction; Suining City has obvious advantages in rural e-commerce cost, even compared with Chengdu City, it still has greater advantages; Nanchong City is better in rural infrastructure construction and rural e-commerce operation cost control. Therefore, these areas should continue to promote the development of rural e-commerce industry, further expand the existing advantages, and further concentrate on making up for the shortcomings, so as to achieve balanced and sustainable development in all aspects.

\section{Reference}

Han, P. (2019). The thriving of e-commerce and the study of embedded entrepreneurship in rural communities in China. Agricultural Economy, (03), 134-136.

Geng, R, Cao, L. (2016). Restrictive factors of rural e-commerce development based on AHP method. Jiangsu Agricultural Science, 44(09), 535-539.

Li, B. (2018). Discussion on the Function Mechanism of E-commerce to Rural Economic Development in China. Business Economic Research, (22), 121-123.

Liu, B., Ye, Y. M., Kang, X. L., \& Wu, C. Y. (2019). Analysis on the choice of farmers'e-commerce entrepreneurship behavior and its influencing factors based on data of 150 farmers' e-commerce entrepreneurs in Jiangxi Province. Journal of Agricultural and Forestry Economic Management, 18(01), 36-42.

Liu, H., \& Ai, C. M. (2018). Establishment of rural e-commerce development evaluation index system based on innovation diffusion theory. China's collective economy, (20), 108-109. https://doi.org/10.1007/s10586-018-1829-4

Luo, S. L. (2016). China's "Internet + rural circulation industry" development problems and improvement measures. Business economics research, (19), 155-157.

Shang, R. (2014). Discussion on the Construction of Rural Circulation System from the Perspective of Informatization. Business Age, (31), 8-9.

Sun, Z. (2019). Strategy of Cooperative Development of E-commerce and Express Logistics in Rural Areas from the Perspective of Rural Revitalization Strategy. Agricultural Economy, (02), 115-117.

Wang, J. J., \& Li, Q. H. (2017). Multidimensional Education and Rural Residents'Entrepreneurship Choice in the E-commerce Environment: An Empirical Analysis Based on the Data of Rural Residents in CFPS 2014 and CHIPS 
2013. Nankai Economic Research, (06), 75-92.

Wang, J. J., Mou, S. H., \& Sheng, Y. X. (2019). Is E-commerce beneficial to rural residents'entrepreneurship? - From the perspective of social capital. Economic and management research, 40(02), 95-110.

Wu, F. (2017). Research on the construction of commercial circulation system under the background of rural modernization. Reform and strategy, 33(01), 57-60.

Yu, S. (2017). Research on the Integration of Rural E-commerce and Traditional Industries. Business Economic Research, (05), 61-63.

Zhang, X. L. (2016). Study on the Establishment of Evaluation Index System of Rural E-commerce. Agricultural Economy, (03), 123-125.

Zheng, Y. Q., \& Zheng, W. S. (2007). Discussion on Establishing Evaluation Index System of Rural Electronic Commerce. Technological Economy, (03), 63-67.

\section{Copyrights}

Copyright for this article is retained by the author(s), with first publication rights granted to the journal.

This is an open-access article distributed under the terms and conditions of the Creative Commons Attribution license which permits unrestricted use, distribution, and reproduction in any medium, provided the original work is properly cited. 